\title{
The backlog
}

\author{
Lloyd R Sutherland MD MSc FRCPC FACP \\ Editor-in-Chief, The Canadian Journal of Gastroenterology, University of Calgary, Calgary, Alberta
}

$\mathrm{T}$ he Oxford Dictionary defines a backlog as either "arrears of uncompleted work" or "a reserve or reserves". For the new Editor-in-Chief and Associate Editors of The Canadian Journal of Gastroenterology, the words of Charles Dickens come to mind: "it was the best of times, it was the worst of times".

When we assumed editorial responsibility for the Journal, we inherited 150 accepted manuscripts. This was the result of the combined efforts of the Founding Editors-in-Chief in 1999 to commission a series of review articles on the primary areas of gastrointestinal disease and physiology. Given the hard work and enthusiasm that they bring to any project that they undertake, the result was not surprising. As might be expected, there is some overlap (ie, achalasia [Hoogerwerf and Pasricha, pages 406-409, and Perracchia and Bonavina, pages 441-443]), but this duplication demonstrates differences in approach, emphasis or understanding.

For the new editors, the good news was that we did not need to worry about having sufficient material for the editorial component of the Journal. Assuming a publication rate of 12 articles per issue, there was sufficient material 'in house' for the year 2000. This has allowed us the time to plan several new initiatives for the Journal (more about this in upcoming issues). On the other hand, the knowledge of the backlog may have discouraged submission of new work to the Journal. Several leading investigators have indicated that they wish to wait until the backlog issue is resolved before submitting their manuscripts.

So what are we doing to meet this challenge? First, we will honour the acceptances of the previous editors. At the same time, we affirm our responsibly to determine the publication priority for each accepted manuscript. This will allow us to develop two publication tracks: one for original research (the most 'time-sensitive' material), the other for brief communi- cations and review articles. By July 2000, we will have published most of the manuscripts dealing with original research accepted by the previous editors. We hope to publish most of the other submissions by the end of the year. Several authors of review articles have kindly updated their manuscripts, and this option is certainly open to all authors. Pulsus Group has agreed that we may also fast-track a limited number of papers. This means that for outstanding submissions, publication could occur within 30 days of acceptance.

Second, we will begin publishing extra issues of the Journal and supplements. An extra issue of the Journal (funded by a grant from the Canadian Association of Gastroenterology) focusing on review articles will be published this summer. A supplement due this summer and funded by Health Canada will focus on viral hepatitis, and a second supplement focusing on inflammatory bowel disease is planned for the later part of 2000.

What is an acceptable backlog? We are aiming for a turnaround time of three months for routine manuscripts and one month for rapid communications or fast-tracked manuscripts. We welcome submissions reporting the results of original research and case reports that illuminate either our understanding of rare diseases or uncommon presentations of common diseases. Review articles, particularly those with either a clinical focus or ones that can translate the new paradigms of basic science into a format that can be accessed by the clinician, are also encouraged. Finally, studies or reviews in support of evidence-based gastroenterology are requested.

We hope that this editorial outlining how we plan to deal with this issue will encourage submission of manuscripts reporting the results of original research as soon as possible. Submission of review articles will be welcomed by the end of summer. 




The Scientific World Journal
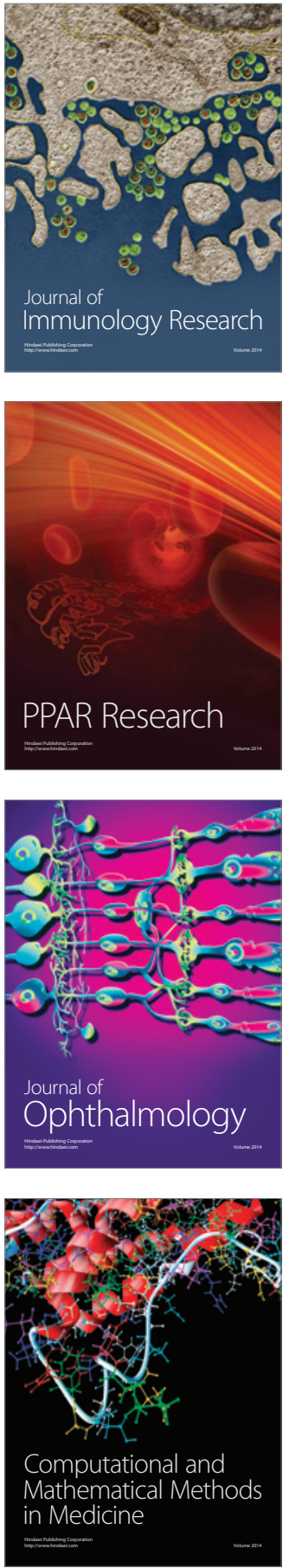

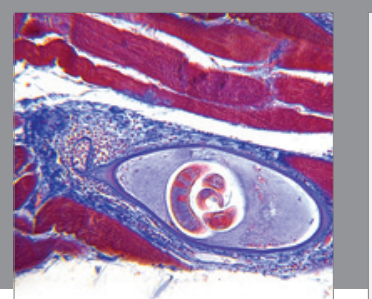

Gastroenterology Research and Practice

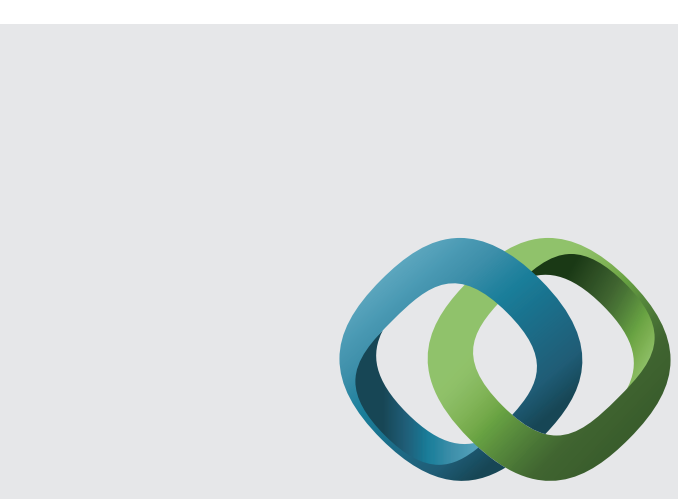

\section{Hindawi}

Submit your manuscripts at

http://www.hindawi.com
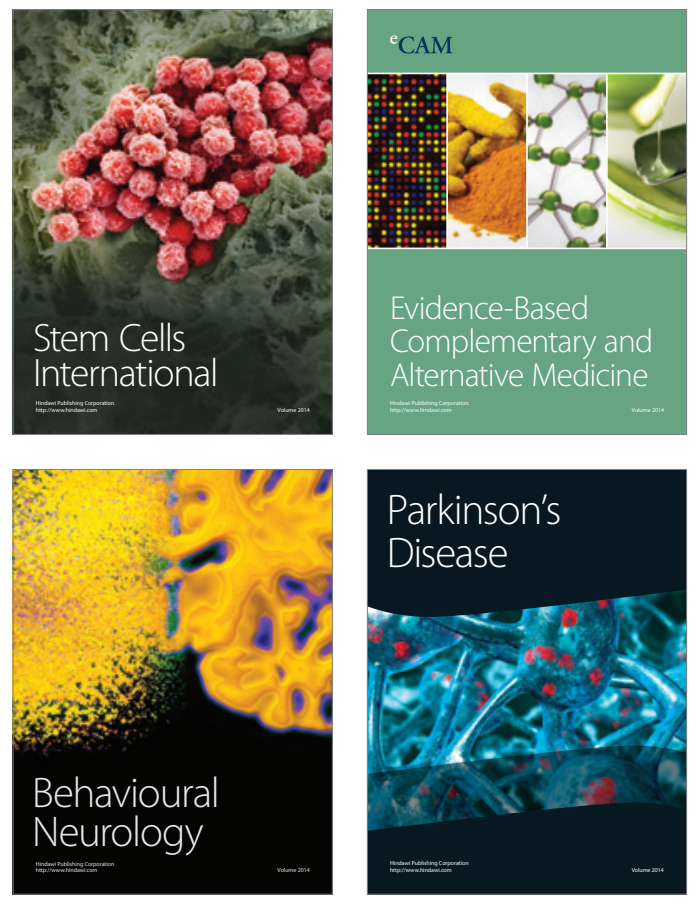
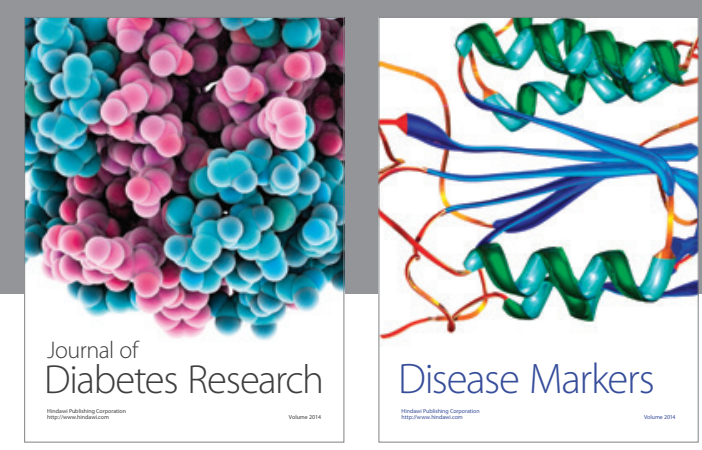

Disease Markers
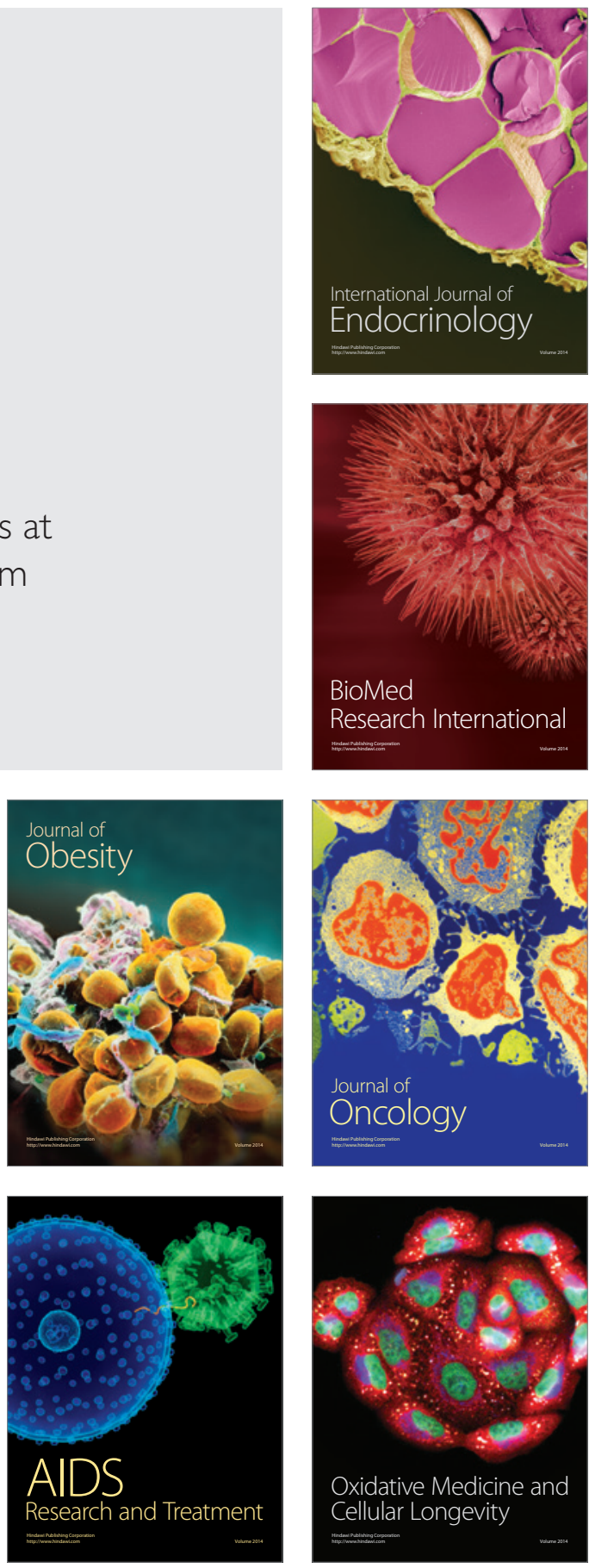